\title{
Folding and Assembly of Hemoglobin Monitored by Electrospray Mass Spectrometry Using an On-line Dialysis System
}

\author{
Brian L. Boys and Lars Konermann \\ Department of Chemistry, The University of Western Ontario, London, Ontario, Canada
}

\begin{abstract}
The native structure of hemoglobin ( $\mathrm{Hb}$ ) comprises two $\alpha$ - and two $\beta$-subunits, each of which carries a heme group. There appear to be no previous studies that report the in vitro folding and assembly of $\mathrm{Hb}$ from highly unfolded $\alpha$ - and $\beta$-globin in a "one-pot" reaction. One difficulty that has to be overcome for studies of this kind is the tendency of $\mathrm{Hb}$ to aggregate during refolding. This work demonstrates that denaturation of $\mathrm{Hb}$ in $40 \%$ acetonitrile at $\mathrm{pH}$ 10.0 is reversible. A dialysis-mediated solvent change to a purely aqueous environment of $\mathrm{pH}$ 8.0 results in $\mathrm{Hb}$ refolding without any apparent aggregation. Fluorescence, Soret absorption, circular dichroism, and ESI mass spectra of the protein recorded before unfolding and after refolding are almost identical. By employing an externally pressurized dialysis cell that is coupled on-line to an ESI mass spectrometer, changes in heme binding behavior, protein conformation, and quaternary structure can be monitored as a function of time. The process occurs in a stepwise sequential manner, leading from monomeric $\alpha$ - and $\beta$-globin to heterodimeric species, which then assemble into tetramers. Overall, this mechanism is consistent with previous studies employing the mixing of folded $\alpha$ - and $\beta$-globin. However, some unexpected features are observed, e.g., a heme-deficient $\beta$-globin dimer that represents an off-pathway intermediate. Monomeric $\beta$-globin is capable of binding heme before forming a complex with an $\alpha$-subunit. This observation suggests that holo- $\alpha$-apo- $\beta$ globin does not represent an obligatory intermediate during $\mathrm{Hb}$ assembly, as had been proposed previously. The on-line dialysis/ESI-MS approach developed for this work represents a widely applicable tool for studying the folding and self-assembly of noncovalent biological complexes. (J Am Soc Mass Spectrom 2007, 18, 8-16) (C 2007 American Society for Mass Spectrometry
\end{abstract}

$\mathrm{T}$ he biologically active state of many proteins comprises several subunits that assemble into a tightly folded quaternary structure. In addition, these complexes often contain functionally essential cofactors. Many of the principles governing the folding of small, monomeric proteins have been uncovered in recent years [1-3]. In contrast, much less is known about the formation of multi-protein assemblies from their unfolded monomeric constituents. Some of these complexes are formed by relatively simple mechanisms, where complete folding of the individual subunits precedes the formation of quaternary contacts [4]. In other cases, however, folding and binding are closely intertwined [5-9]. One difficulty encountered during many in vitro studies on the folding and assembly of protein complexes is the occurrence of aggregation. Another problem is the fact that most spectroscopic techniques cannot readily distinguish intramolecular structural changes from those that are linked to the formation of intermolecular contacts [4].

Published online September 18, 2006

Address reprint requests to Dr. L. Konermann, Department of Chemistry, The University of Western Ontario, London, ON, N6A 5B7, Canada. E-mail: konerman@uwo.ca
Direct insights into the structure and dynamics of protein complexes can be obtained by electrospray ionization (ESI) mass spectrometry (MS). The gentle nature of the ESI process allows a wide range of noncovalent assemblies to be transferred into the gas-phase, such that their composition can be determined from their mass [10-13]. In addition, the ESI charge state distribution provides a highly sensitive probe for changes in the overall protein conformation. Unfolded solution-phase proteins generally produce higher charge states during positive ion ESI than tightly folded structures [14-16]. As a result, ESI-MS is rapidly being adopted as a standard method in structural biology [17].

Hemoglobins $(\mathrm{Hb})$ from higher organisms are among the most thoroughly studied multi-protein complexes. The quaternary structure of $\mathrm{Hb}$ comprises two pairs of heme containing $\alpha$ - and $\beta$-subunits in a tetrahedral arrangement. The noncovalent bonds stabilizing this complex encompass nonpolar and van der Waals interactions, hydrogen bonds, and salt bridges. Each $\alpha$ chain impinges upon the two $\beta$ chains along two different surfaces. The noncovalent contacts connecting the $\alpha 1 \beta 1$ and $\alpha 2 \beta 2$ subunits are more extensive than those found at the $\alpha 1 \beta 2$ and $\alpha 2 \beta 1$ interfaces [18, 19]. The cooperative binding of oxygen to $\mathrm{Hb}$ is a particu- 
larly important area of research. Although the basic principles underlying the oxy $(\mathrm{R})$ to deoxy $(\mathrm{T})$ transition have been elucidated several decades ago [20], new details regarding the mechanism of these structural switching events continue to emerge [21-24].

$\mathrm{Hb}$ also serves as an important model system for studying protein assembly. The canonical heterotetrameric structure is in equilibrium with $\alpha \beta$ dimers as well as with $\alpha$ - and $\beta$-monomers [25]. Adding to this complexity is the fact that, in principle, every subunit can exist in its heme-bound form (holo, i.e., $\alpha^{\mathrm{h}}$ and $\beta^{\mathrm{h}}$ ) or in its heme-free form (apo, i.e., $\alpha^{\mathrm{a}}$ and $\beta^{\mathrm{a}}$ ) [26]. Removal of heme causes the subunits to adopt extensively disordered structures [27]. Previous studies on the binding equilibria and assembly of $\mathrm{Hb}$ mostly employed UV-Vis spectral changes in the Soret region of the heme absorption spectrum. Occasionally, this was complemented by CD and fluorescence spectroscopic measurements $[27,28]$. Other studies were based on measurements of haptoglobin binding [29], autooxidation kinetics [30], radioactive labeling [31], as well as stopped-flow $\mathrm{pH}$ measurements [32]. The in vitro assembly of $\mathrm{Hb}$ has most commonly been triggered by mixing initially separated $\alpha^{\mathrm{h}}$ and $\beta^{\mathrm{h}}$ subunits under native solvent conditions. Before mixing, the isolated subunits form noncovalently bound $\left(\alpha^{\mathrm{h}}\right)_{2}$ and $\left(\beta^{\mathrm{h}}\right)_{4}$ complexes, respectively. Dissociation of these species allows the formation of $\alpha \beta$ dimers to occur, which can then form heterotetrameric $\mathrm{Hb}$ [33-38]. Electrostatic interactions play a key role in guiding these assembly processes [39-41]. The exact heme-binding state of the dimeric $\alpha \beta$ intermediate(s) $\left(\alpha^{\mathrm{h}} \beta^{\mathrm{h}}, \alpha^{\mathrm{h}} \beta^{\mathrm{a}}, \alpha^{\mathrm{a}} \beta^{\mathrm{h}}\right.$, or $\left.\alpha^{\mathrm{a}} \beta^{\mathrm{a}}\right)$ is still a matter of debate [28, 42-44], and apparently there is more than one viable assembly pathway leading from the isolated subunits to native $\mathrm{Hb}$ [45].

The in vivo mechanism of $\mathrm{Hb}$ formation is thought to partly resemble that inferred from in vitro studies [46]. It is important to note, however, that during $\mathrm{Hb}$ biosynthesis the monomeric subunits undergo co-translational folding and heme binding [47, 48]. Another interesting aspect is the recent discovery of a chaperone in red blood cell precursors. This chaperone, termed AHSP ( $\alpha$-hemoglobin-stabilizing protein), specifically binds to nascent monomeric $\alpha^{\mathrm{h}}$, thereby preventing the formation of cytotoxic $\alpha$-globin aggregates [46, 49-54].

To our knowledge, there exist no previous studies that report the in vitro folding and assembly of $\mathrm{Hb}$ from extensively denatured $\alpha$ - and $\beta$-subunits in a "one-pot" reaction. Such a process would have to involve (1) the folding of individual subunits, (2) subunit binding to heme, and (3) subunit assembly to form tetrameric $\mathrm{Hb}$ (obviously, the three steps do not necessarily have to occur in this particular order). Previous attempts to carry out related experiments were frustrated by very low heterotetramers yields due to extensive aggregation and precipitation [55]. In fact, aggregation is a common problem even for reconstitution schemes employing folded $\alpha$ - and $\beta$-subunits [45]. This ${ }^{\circ}$ could imply that $\mathrm{Hb}$ folding and self-assembly necessarily requires a chaperone system, and possibly other components of the cellular machinery. However, the experiments described in the current study demonstrate that this is not the case. We employ a dialysis system that is coupled on-line to an ESI mass spectrometer, such that conformational changes, as well as the formation of hemeprotein and protein-protein contacts can be monitored directly. Under carefully controlled solution conditions the gradual removal of denaturants from a $\mathrm{Hb}$ solution causes the protein to refold and assemble without any apparent aggregation.

\section{Experimental}

\section{Materials}

Bovine ferri-Hb (Sigma, St. Louis, MO) was dialyzed against $10 \mathrm{mM}$ ammonium acetate (Fluka, Buchs, Switzerland). All stock $\mathrm{Hb}$ solutions were made to $1 \mathrm{mM}$ (as tetramer) and were centrifuged to remove small amounts of insoluble debris. Post-dialysis samples were flash frozen in liquid nitrogen as $100 \mu \mathrm{L}$ aliquots and stored at $-80{ }^{\circ} \mathrm{C}$. All $\mathrm{Hb}$ solutions contained $10 \mathrm{mM}$ ammonium acetate. Reagent grade ammonium hydroxide and glass distilled acetonitrile (ACN) were obtained from Caledon Laboratories, Georgetown, ON. Consistent with previous reports, the subunit masses of the protein were found to be 15,053 Da and 15,954 Da for $\alpha^{\mathrm{a}}$ and ${ }^{\circ} \beta^{\mathrm{a}}$, ${ }^{\circ}$ respectively ${ }^{\circ}[56]^{\circ} .^{\circ}$ The $^{\circ}$ heme $^{\circ}$ group ${ }^{\circ}$ accounts ${ }^{\circ}$ for an additional $616 \mathrm{Da}$ for each subunit. Both $\beta$-subunits have a ${ }^{\circ}$ reduced ${ }^{\circ} \mathrm{Cys}$ 'residuein position $^{9}$ 9321]. ESI'mass spectra recorded under denaturing acidic conditions confirmed that no intermolecular disulfide bridging took place under any of the conditions used in this work (data not shown). In contrast to physiologically active ferro $\left(\mathrm{Fe}^{2+}\right) \mathrm{Hb}$, the ferri $\left(\mathrm{Fe}^{3+}\right)$ form of the protein used here ("metHb") is not capable of reversible oxygen binding. $\mathrm{Fe}^{2+} \rightarrow \mathrm{Fe}^{3+}$ auto-oxidation occurs readily upon exposure of the protein to air. The X-ray crystal structure of ferri- $\mathrm{Hb}$ corresponds to that of ferro- $\mathrm{Hb}^{\circ}$ in $^{\circ}$ its $^{\circ} \mathrm{R}^{\circ}$ conformation ${ }^{\circ}[19]$.

\section{On-line Dialysis}

To monitor the refolding and assembly of $\mathrm{Hb}$ from its denatured constituent parts, an on-line dialysis setup was developed. $\mathrm{Hb}(50 \mu \mathrm{M}$ as tetramer) was denatured by first raising the $\mathrm{pH}$ from 6.8 to 10.0 (ammonium hydroxide), subsequently $\mathrm{ACN}$ was added to a final concentration of $40 \%$ ( $\mathrm{vol} / \mathrm{vol})$. After exposing the protein to these conditions for ca. $10 \mathrm{~min}, 2.8 \mathrm{~mL}$ of the $\mathrm{Hb}$ solution were transferred into a slide-A-Lyzer dialysis cassette (Pierce, Rockford, IL) with a nominal 7 kDa molecular weight cut-off. Refolding commenced after placing this cassette in an air tight screw-cap container filled with $2.8 \mathrm{~L}$ of dilute ammonium hydroxide $(\mathrm{pH}$ 7.90). Equilibration of the protein solution with the dialysis buffer resulted in $\mathrm{pH} 8.0$ and less than $0.04 \%$ ACN. Refolding was monitored as a function of dialysis 


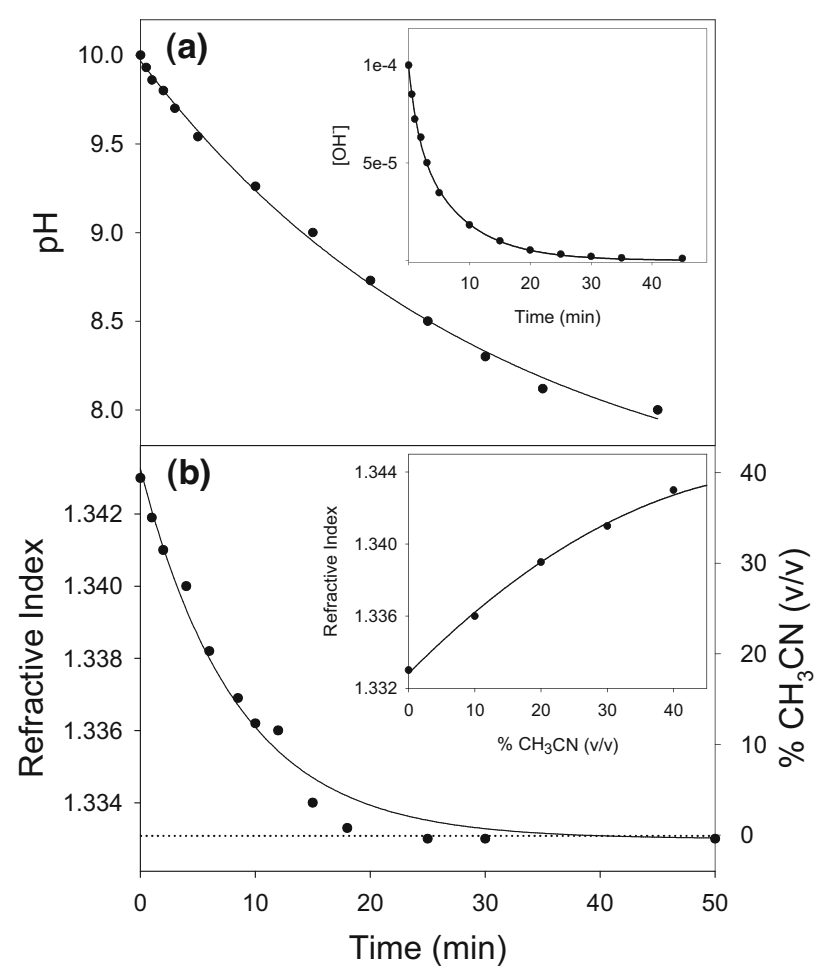

Figure 1. $\mathrm{pH}$ and acetonitrile $(\mathrm{ACN})$ concentration changes during on-line dialysis. (a) $\mathrm{pH}$ as a function of time; the inset shows the same data after conversion to hydroxide ion concentration. (b) Refractive index as a function of time, reflecting the drop in ACN concentration within the solution during dialysis. The dotted line indicates the refractive index of water $(n=1.333)$. Inset: calibration curve used to determine the ACN concentration. Filled circles represent experimental data, solid lines are spline curves.

time by pressurizing the headspace within the container with nitrogen, causing the protein solution to exit the dialysis cassette via a metal capillary, that was directly connected to the ESI source of the mass spectrometer via PEEK tubing. A nitrogen pressure of 3 psi resulted in an analyte flow rate of $30 \mu \mathrm{L} \mathrm{min}^{-1}$, corresponding to a flow delay of ca. 2 min between the dialysis cassette and the outlet of the ESI source. Time-dependent changes of $\mathrm{pH}$ and $\mathrm{ACN}$ concentrations within the dialysis cell were monitored with an $\mathrm{AB} 15 \mathrm{pH}$ meter (Fisher Scientific, Nepean, $\mathrm{ON}$ ) and Atago refractometer ${ }^{\circ}$ HSR-500, ${ }^{\circ}$ Atago, ${ }^{\circ}$ Tokyo, ${ }^{\circ}$ Japan), ${ }^{\circ}$ respectively, ${ }^{\circ}$ (Figure $\left.{ }^{\circ} 1\right)$. ${ }^{\circ}$ The ${ }^{\circ}$ total ${ }^{\circ}$ protein ${ }^{\circ}$ oss $^{\circ}$ upon ${ }^{\circ}$ refolding ${ }^{\circ}$ was ${ }^{\circ}$ found to be ca. $25 \%$ by UV-Vis spectroscopy. We attribute this loss to protein leakage through the dialysis membrane, despite the nominal $7 \mathrm{kDa}$ cut-off. In addition, protein adsorption to the membrane may play a role.

\section{ESI-MS}

Online dialysis was monitored with an LCT timeof-flight mass spectrometer (Waters/Micromass, Manchester, UK) employing a commercial Z-spray source operating in positive ion mode. All MS parameters were optimized to give the best $\mathrm{Hb}$ tetramer signal at $\mathrm{pH}$ 8.0. A capillary voltage of $3.5 \mathrm{kV}$, extraction cone voltage of $10 \mathrm{~V}$, and sample cone voltage of $60 \mathrm{~V}$ were found to be optimal. Desolvation and source temperatures (30 and $80^{\circ} \mathrm{C}$, respectively) were kept low to minimize tetramer dissociation. The mass spectrometer was operated at elevated pressure in the first pumping stage to facilitate the detection of noncovalent com-

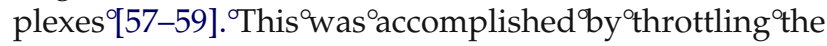
source turbo pump by means of a speedy valve to a pressure reading of 10 mbar. $\mathrm{Hb}$ refolding was monitored as a function of dialysis time, as explained above, with a scan time of $2 \mathrm{~s}$ for $40 \mathrm{~min}$. Spectra were grouped and averaged every $2 \mathrm{~min}$ from 0 to $10 \mathrm{~min}$, then every $5 \mathrm{~min}$ from 10 to $20 \mathrm{~min}$ and, finally, every $10 \mathrm{~min}$ from 20 to $40 \mathrm{~min}$. Normalized peak intensity traces for all species present were generated from these nine spectra. The mass spectrometer was calibrated with CsI. All data were acquired and analyzed using MassLynx software provided by the instrument manufacturer. Baseline subtraction and data smoothing was performed before analysis.

\section{Optical Spectroscopy}

Fluorescence emission spectra were measured on a PTI fluorimeter (Mississauga, ON, Canada) using an excitation wavelength of $280 \mathrm{~nm}$. All solutions analyzed contained $5 \mu \mathrm{M} \mathrm{Hb}$ (as tetramer). Absorption measurements were carried out on a Cary-300 Varian UV-Vis spectrometer (Palo Alto, CA) using a protein concentration of $2.5 \mu \mathrm{M}$. Circular dichroism (CD) spectra were collected on a Jasco J-810 spectropolarimeter (Easton, MD) by employing a $0.1 \mathrm{~cm}$ path length cuvette and 5 $\mu \mathrm{M} \mathrm{Hb}$.

\section{Results and Discussion}

\section{Reversible and Irreversible Denaturation of Hemoglobin}

Griffith and Kaltashov recently conducted a detailed study on the disassembly and unfolding of $\mathrm{Hb}$ by monitoring ESI mass spectra at increasing acid concentrations ${ }^{\circ}[60] .{ }^{\circ}{ }^{\circ}$ Ionic ${ }^{\circ}$ signals $^{\circ}{ }^{\circ}$ corresponding ${ }^{\circ}$ to $^{\circ}$ the ${ }^{\circ}$ native $\mathrm{Hb}$ tetramer were most intense around $\mathrm{pH}$ 8.0. Acidification was found to disrupt the tetramer, initially leading to the formation of $\alpha^{\mathrm{h}} \beta^{\mathrm{h}}$ and $\alpha^{\mathrm{h}} \beta^{\mathrm{a}}$ dimers which dominate the spectrum at $\mathrm{pH} 5$. These dimeric structures become unstable below $\mathrm{pH} \mathrm{4,} \mathrm{forming} \mathrm{highly}$ unfolded monomeric apo-subunits around $\mathrm{pH} 3$. This stepwise process resembles the denaturation mechanism observed in kinetic ESI-MS experiments, where unfolding ${ }^{\circ}$ was $^{\circ}$ triggered ${ }^{\circ} \mathrm{by}^{\circ} \mathrm{a}^{\circ}$ sudden ${ }^{\circ} \mathrm{pH}^{\circ}$ jump ${ }^{\circ}[61]$.

Unfolding studies can provide direct information on the refolding mechanism of a protein only if the experiments are carried out under reversible conditions. Unfortunately, the acidic $\mathrm{pH}$ environment employed previously ${ }^{\circ}\left[60,{ }^{\circ} 61\right]^{\circ}$ results $^{\circ}$ in ${ }^{\circ}$ irreversible ${ }^{\circ}$ denaturation of $\mathrm{Hb}$. For the current work it was attempted to refold 
(a)

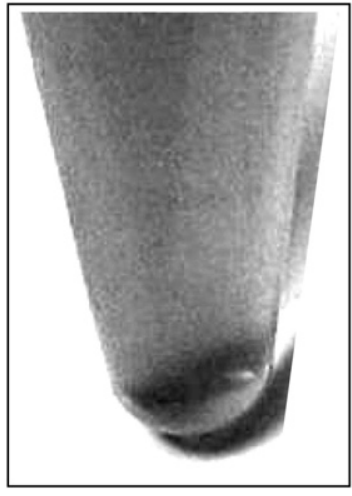

(c)

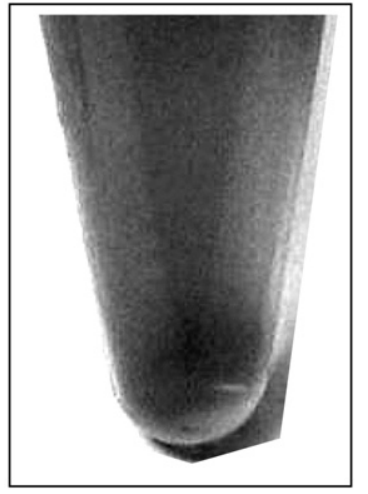

(d)

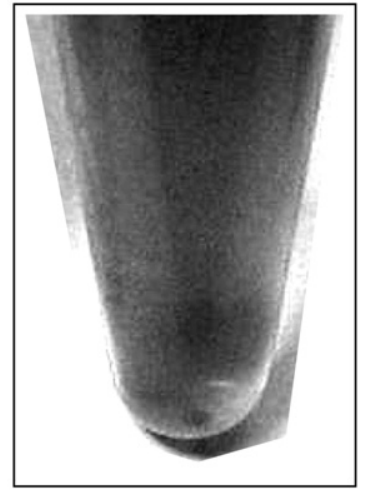

Figure 2. Photographs of microtubes after centrifugation of hemoglobin solutions at 10,000 rpm for $10 \mathrm{~min}$. (a) Acid-denatured protein in $10 \%$ acetic acid (no pellet); (b) initially aciddenatured protein after exchange into aqueous solution at $\mathrm{pH}$ 8.0. Note the pellet of precipitated protein (indicated by the arrow); (c) denatured protein at $\mathrm{pH} 10.0$ in water/ACN (60:40 vol/vol) (no pellet); (d) initially base/ACN denatured protein, refolded by exchange into aqueous solution at $\mathrm{pH} 8.0$ (no pellet).

the acid-denatured protein in different ways, e.g., by slowly titrating it back to $\mathrm{pH} 8.0$, or by carrying out a single-step $\mathrm{pH}$ change. Extensive protein aggregation

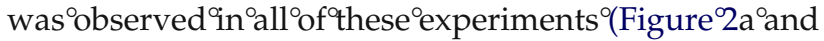
b). ESI-MS analysis of the supernatant obtained after centrifugation did not reveal the presence of any refolded protein. In contrast, we found hemoglobin denaturation at $\mathrm{pH} 10.0$ in $40 \%$ (vol/vol) $\mathrm{ACN}$ to be reversible. A dialysis-mediated change in conditions back to a purely aqueous solution of $\mathrm{pH} 8.0$ does not result ${ }^{\circ} n^{\circ} a n y^{\circ}$ detectable aggregation $\left(\right.$ Figure $^{\circ} \mathrm{c}^{\circ}$ and $\left.{ }^{\circ} \mathrm{d}\right)$. It seems likely that one contributing factor for the different behavior observed for the two denaturing conditions is the fact that heme itself tends to precipitate in acidic solution due to its very low solubility. Under these conditions, refolding may be limited by the lack of freely available heme, which is required for both globin chain ${ }^{\circ}$ to ${ }^{\circ}$ fold $^{\circ}$ into ${ }^{\circ} \mathrm{a}^{\circ}$ compact $^{\circ}$ conformation $^{\circ}[27] . .^{\circ} \mathrm{As}^{\circ} \mathrm{a}$ result, the polypeptide chains can become trapped in conformations that are prone to aggregation. At basic $\mathrm{pH}$ this problem does not occur due to the much higher heme ${ }^{\circ}$ solubility $\{62,63]$. The ${ }^{\circ}$ data ${ }^{\circ}$ discussed below ${ }^{\circ}$ show that refolded $\mathrm{Hb}$ after exposure to $\mathrm{pH} 10.0 / 40 \%$ ACN closely resembles the native protein before denaturation.

\section{Characterization of Denatured Hb by ESI-MS}

Figure ${ }^{\circ} 3 \mathrm{a}^{\circ}$ depicts $^{\circ} \mathrm{a}^{\circ}$ typical $^{\circ} \mathrm{ESI}^{\circ}$ mass $^{\circ}$ spectrum $^{\circ}$ of ${ }^{\circ} \mathrm{Hb}$ obtained at $\mathrm{pH}$ 8.0, before exposing the protein to denaturing conditions. Consistent with previous work

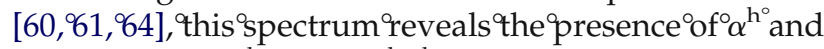
$\beta^{\mathrm{a}}$ monomers, $\alpha^{\mathrm{h}} \beta^{\mathrm{a}}$ and $\alpha^{\mathrm{h}} \beta^{\mathrm{h}}$ dimers, and $\mathrm{Hb}$ heterotetramers. These gas-phase species reflect the presence of the corresponding solution-phase quaternary structures and are consistent with the known binding equilibria of

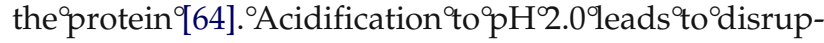
tion $^{\circ}$ of $^{\circ}$ all $^{\circ}$ protein-protein ${ }^{\circ}$ interactions ${ }^{\circ}$ (Figure $3 b$ ). ESI-MS data obtained under these conditions exclusively show $\alpha^{\mathrm{a}}$ and $\beta^{\mathrm{a}}$ ions which, based on their charge state distributions, represent highly unfolded solutionphase ${ }^{\circ}$ structures $\left.960,16,65\right]$. The ${ }^{\circ}$ spectrum ${ }^{\circ}$ of ${ }^{\circ}$ reversibly denatured $\mathrm{Hb}(\mathrm{pH} 10.0 / 40 \% \mathrm{ACN})$ is somewhat more complex $^{\circ}\left(\right.$ Figure $\left.^{\circ} 3 \mathrm{c}\right) .^{\circ}$ It $^{\circ}$ exhibits $^{\circ} \mathrm{a}^{\circ}$ bimodal $^{\circ} \alpha^{\mathrm{a}^{\circ}}$ charge state distribution. The most intense charge states around $14+$ are attributed to apo- $\alpha$-globin that is unfolded to a similar degree as under acidic conditions, whereas $\alpha^{\mathrm{a}}$ ions around $8+$ indicate the presence of apo- $\alpha$-globin in a more compact solution-phase conformation. A similar bimodal distribution at lower intensity is observed for $\alpha^{\mathrm{h}}$ ions, representing monomeric $\alpha$-globin that maintains contact with its heme-cofactor, resembling the behavior observed for myoglobin under similar ${ }^{\circ}$ solvent ${ }^{\circ}$ conditions $^{\circ}[66]^{\circ}{ }^{\circ}$ Both ${ }^{\circ}$ holo- ${ }^{\circ}$ and ${ }^{\circ}$ apo- $\beta$ globin appear in charge states $7+$ up to at least $14+$. In addition, the spectrum shows dimers of the composition $\beta^{\mathrm{a}} \beta^{\mathrm{h}}$.

As an interesting side aspect, it is noted that the solution charge states of apo- $\alpha$-globin at $\mathrm{pH} 2.0$ and 10.0 are ca. $25+$ and $4-$, respectively. Yet, the corresponding ESI $^{\circ}$ charge $^{\circ}$ state $^{\circ}$ distributions $^{\circ}$ in $^{\circ}$ Figure $^{\circ} 3 \mathrm{~b}^{\circ}$ and ${ }^{\circ} \mathrm{c}^{\circ}$ both exhibit a maximum around $14+$. This observation is consistent with the notion that the protein charge states observed in ESI-MS are not determined by the charges of the protein in solution, rather the ESI charge states are determined by the solution-phase protein conformation'[67].

\section{Characterization of Denatured and Refolded $\mathrm{Hb}$ by Optical Spectroscopy}

The Trp fluorescence intensity of native $\mathrm{Hb}$ at $\mathrm{pH} 8.0$ is relatively low. A dramatically increased emission level is observed upon exposure of the protein to $\mathrm{pH} 2.0$, and an even higher intensity is seen at $\mathrm{pH} 10.0$ in $40 \% \mathrm{ACN}$ (Figure $\left.{ }^{\circ} 4 a\right) .^{\circ} \operatorname{In}^{\circ}$ native ${ }^{\circ}$ hemoglobin ${ }^{\circ}$ the ${ }^{\circ}$ fluorescence ${ }^{\circ}$ of $\alpha \operatorname{Trp} 14, \beta \operatorname{Trp} 15, \beta \operatorname{Trp} 37$ is quenched by Förster reso- 


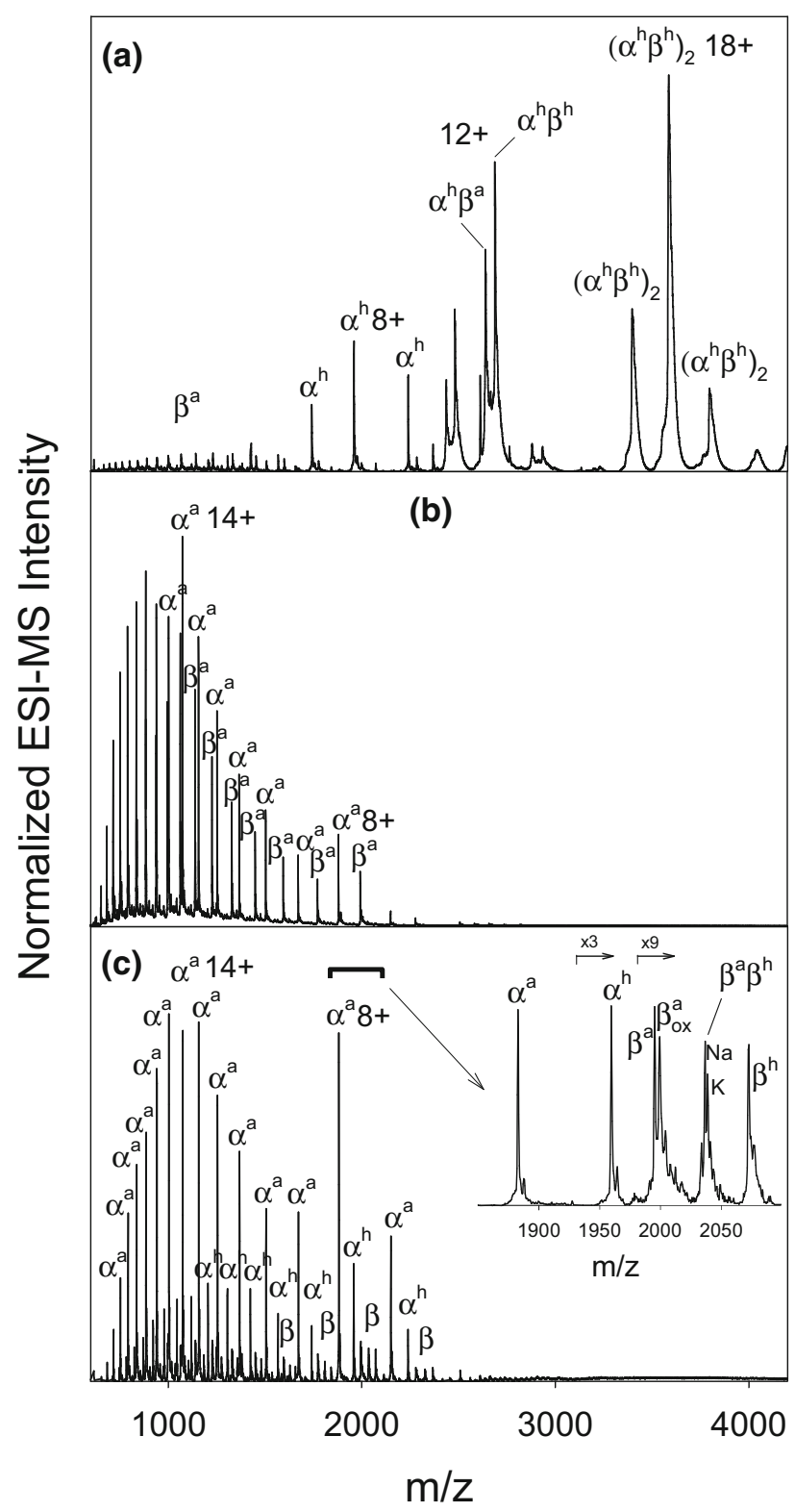

Figure 3. ESI mass spectra of hemoglobin recorded under different solvent conditions. (a) "Native", aqueous solution, $\mathrm{pH}$ 8.0; (b) acid-unfolded, aqueous solution, $\mathrm{pH} 2.0$; (c) unfolded protein at $\mathrm{pH} 10.0$ in water/ACN (60:40 vol/vol). Notation: $\alpha^{\mathrm{h}}$ and $\alpha^{\mathrm{a}}$ represent holo- and apo- $\alpha$-globin, respectively; $\beta$-globin is labeled analogously. (c) inset: expansion of the region around $\mathrm{m} / \mathrm{z} 2000$, revealing the presence of both $\alpha$ - and $\beta$-subunits in their apo and holo forms. $\beta_{\text {ox }}^{\text {a }}$ represents an $(\mathrm{M}+32)$ species. The expanded spectrum also shows signals corresponding to $\beta^{\mathrm{a}} \beta^{\mathrm{h}}$ ions carrying $\mathrm{Na}^{+}$and $\mathrm{K}^{+}$adducts.

nance ${ }^{\circ}$ energy-transfer ${ }^{\circ} 0^{\circ}$ the ${ }^{\circ}$ nonfluorescent ${ }^{\text {Themes }} 968^{\circ}$ 70]. ${ }^{\circ}$ Protein ${ }^{\circ}$ unfolding $^{\circ}$ and ${ }^{\circ}$ disruption ${ }^{\circ}$ of ${ }^{\circ}$ the ${ }^{\circ}$ heme/ protein interactions leads to increased heme-Trp distances, thereby reducing the energy-transfer effi-

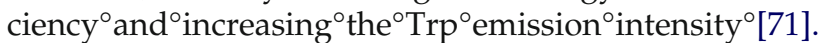
Control experiments on $\mathrm{N}$-acetyl tryptophan amide indicate that the lower emission intensity seen at $\mathrm{pH} 2.0$ is due to solvent-chromophore interactions, not to a lesser degree of unfolding when compared to $\mathrm{pH} 10.0$ / $40 \%$ ACN (data not shown).
Changes in the heme environment can be probed by monitoring the Soret region of the heme absorption spectrum. Hemoglobin at $\mathrm{pH} 8.0$ exhibits a narrow spectral $^{\circ}$ band $^{\circ}$ with $^{\circ} a^{\circ}$ maximum ${ }^{\circ}$ at $^{\circ} 406^{\circ} \mathrm{nm}^{\circ}$ (Figure ${ }^{\circ} 4 \mathrm{~b}$ ). Denaturation at $\mathrm{pH} 10.0 / 40 \% \mathrm{ACN}$ leads to lowering of the absorption intensity, broadening of the spectrum, and a slight blue shift. Even more pronounced changes are observed upon exposing the protein to $\mathrm{pH}$ 2.0. The protein absorption spectra recorded under both acidic and basic conditions resemble those of isolated heme in the corresponding solvents (data not shown).

Far-UV CD spectroscopy provides information on secondary ${ }^{\circ}$ structure $\left[17,{ }^{\circ} 72\right] .{ }^{\circ} \mathrm{Hb}^{\circ}$ at $^{\circ} \mathrm{pH}^{\circ} 8.0^{\circ}$ exhibits $^{\circ}$ with
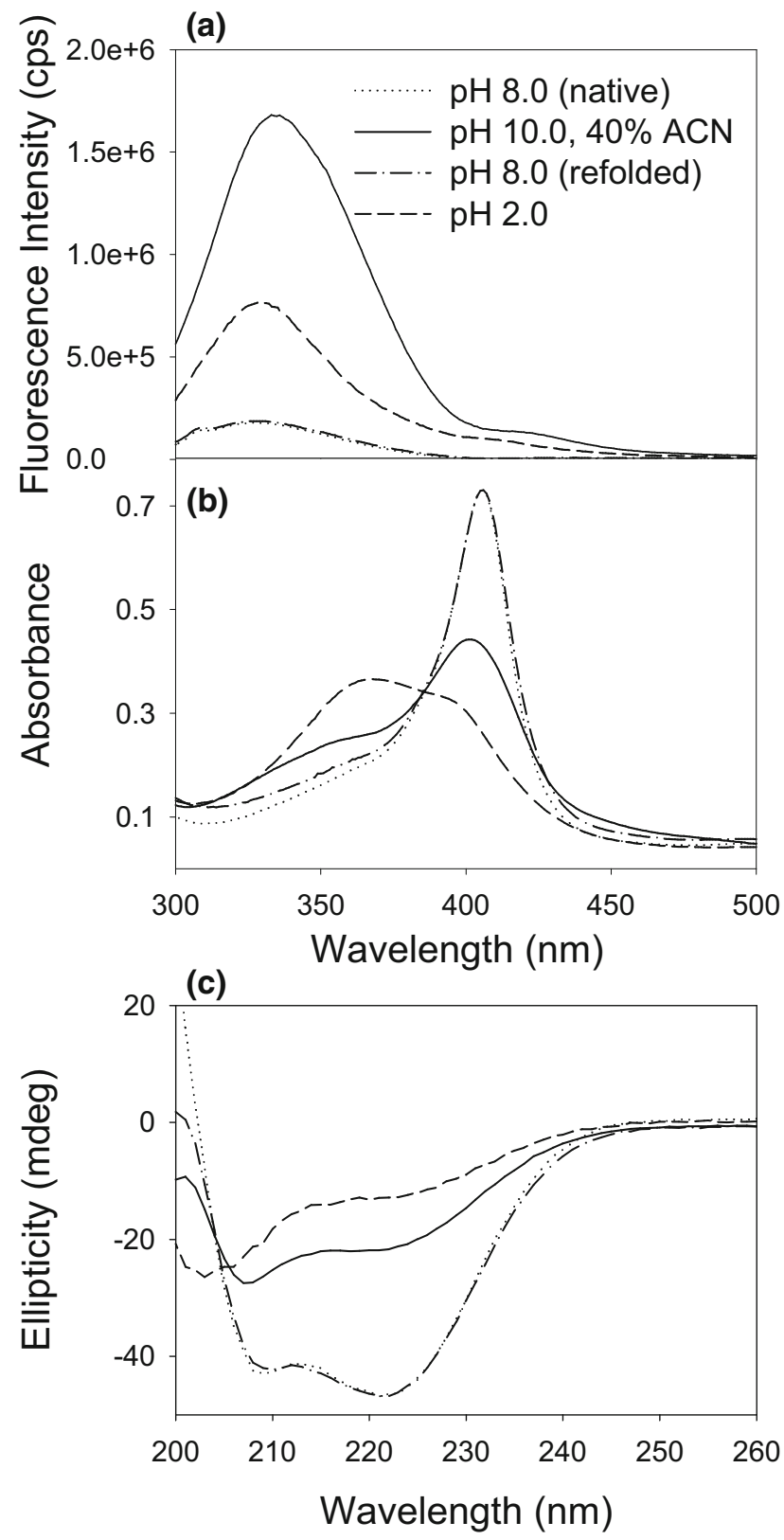

Figure 4. Characterization of native, denatured, and refolded hemoglobin by optical spectroscopy. (a) Fluorescence emission, (b) Soret absorption, and (c) circular dichroism spectra. The various solvent conditions used are indicated in (a). 
two pronounced minima around 208 and $222 \mathrm{~nm}$, which reflect the protein's largely helical conformation. Upon exposing $\mathrm{Hb}$ to $\mathrm{pH} 10.0 / 40 \% \mathrm{ACN}$ the intensity of the CD signal at $222 \mathrm{~nm}$ is diminished by ca. $50 \%$, which suggests that the protein looses about half of its native helicity under these conditions. An even more pronounced loss of helicity (ca. 75\%) is observed for the acid-denatured protein (Figure 4c).

The optical data reported here are consistent with the ESI-MS spectra of Figure 3, confirming that $\mathrm{Hb}$ at $\mathrm{pH}$ $10.0 / 40 \%$ ACN adopts a significantly unfolded structure. The native heme-protein interactions are largely disrupted and the heme groups are mostly solventaccessible. Yet, the persistence of weak residual hemeprotein interactions under these non-native conditions is quite likely [66, 73], which is supported by the observation of low intensity heme-bound species by ESI-MS (Figure 3c). Also, "free" heme would get lost during dialysis, thus precluding refolding of the protein. CD spectroscopy (Figure 4c) shows that $\mathrm{Hb}$ at $\mathrm{pH}$ 2.0 is more extensively unfolded than the protein in its reversibly denatured form, a result that is in line with the charge state distributions displayed in Figure $3 b$ and c. The most important aspect of Figure 4 is that the fluorescence, absorption, and CD spectra obtained after dialysis-mediated refolding of the base-denatured protein are indistinguishable from those of native $\mathrm{Hb}$ (the dotted spectra almost perfectly match the dash-dotted ones in all three panels of Figure 4).

\section{Hemoglobin Refolding Monitored by ESI-MS}

The dialysis setup developed for this work allows the folding and reassembly of $\mathrm{Hb}$ to be monitored in an on-line fashion by ESI-MS. Mass spectra were recorded while the solvent inside the dialysis chamber was gradually changed from $\mathrm{pH} 10.0 / 40 \% \mathrm{ACN}$ to a purely aqueous environment of $\mathrm{pH}$ 8.0. The spectrum measured after a dialysis time of one minute (Figure 5a) is similar to that obtained under the denaturing conditions of Figure 3c. After $3 \mathrm{~min}$, the relative intensities of highly charged $\alpha^{\mathrm{a}}$ ions are greatly diminished, and $\alpha^{\mathrm{h}}$ $8+$ has become the most intense peak (Figure $5 b$ ). This spectral change reflects the transition of unfolded apo$\alpha$-globin to a more compact holo- $\alpha$-globin conformation. Heme-bound heterodimers are the dominant species for a dialysis time of $9 \mathrm{~min}$ (Figure 5c). The spectrum recorded after $35 \mathrm{~min}$ shows tetramers, hemebound and heme-deficient dimers, $\alpha^{\mathrm{h}}$ ions in low charge states, and a small contribution from $\beta^{\text {a }}$ ions in high charge states (Figure $5 \mathrm{~d}$ ). This spectrum resembles that recorded for native $\mathrm{Hb}$ (Figure 3a), confirming that the quaternary structure after refolding is similar to that before denaturation. The slightly higher tetramer intensities and lower $\alpha^{\mathrm{h}}$ intensities, however, indicate the presence of minor structural differences, despite the fact that the corresponding optical spectra are indistinguishable.

For a better visualization of the spectral changes taking place during refolding, the peak intensities of

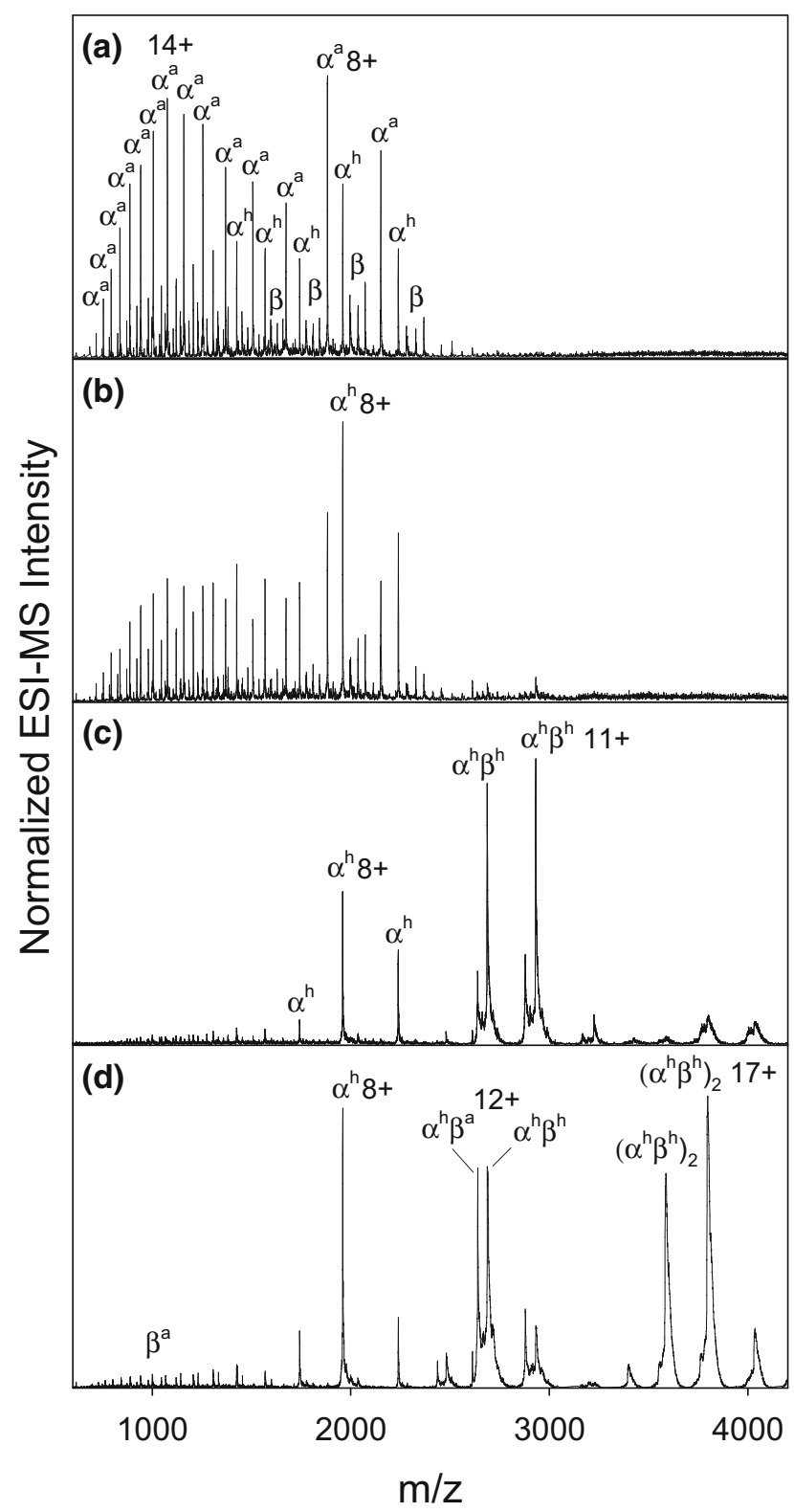

Figure 5. ESI mass spectra recorded during hemoglobin refolding in an on-line dialysis cell. (a) $\mathrm{t}=1 \mathrm{~min} ;(\mathbf{b}) \mathrm{t}=3 \mathrm{~min} ;(\mathbf{c}) \mathrm{t}=$ 9 min; (d) $t=35$ min.

gas-phase ions corresponding to individual solutionphase species were added and normalized, resulting in the traces depicted in Figure 6. Within the first $10 \mathrm{~min}$, the signals of $\alpha^{\mathrm{a}}, \beta^{\mathrm{a}}$, and $\beta^{\mathrm{h}}$ decrease to levels close to zero (Figure $6 \mathrm{a}, \mathrm{b}$, and $\mathrm{d}$ ). Following an initial increase, the time profile of $\alpha^{\mathrm{h}}$ in charge states $9+$ to $23+$ exhibits a drop and then levels off at an intensity around 0.1. The lower charge states of $\alpha^{\mathrm{h}}$ increase to an intensity level of 0.2 within ca. 15 min (Figure 6c). The $\beta^{\mathrm{a}} \beta^{\mathrm{h}}$ dimer is most strongly populated around $5 \mathrm{~min}$, later on it completely disappears from the spectrum. Figure $6 \mathrm{f}-\mathrm{h}$ displays the traces of three species that were not populated at the onset of the reaction. A sigmoidal rise to 0.17 is seen for $\alpha^{\mathrm{h}} \beta^{\mathrm{a}}$ (Figure $6 \mathrm{f}$ ), whereas the trace for $\alpha^{\mathrm{h}} \beta^{\mathrm{h}}$ exhibits its highest intensity around ten minutes 


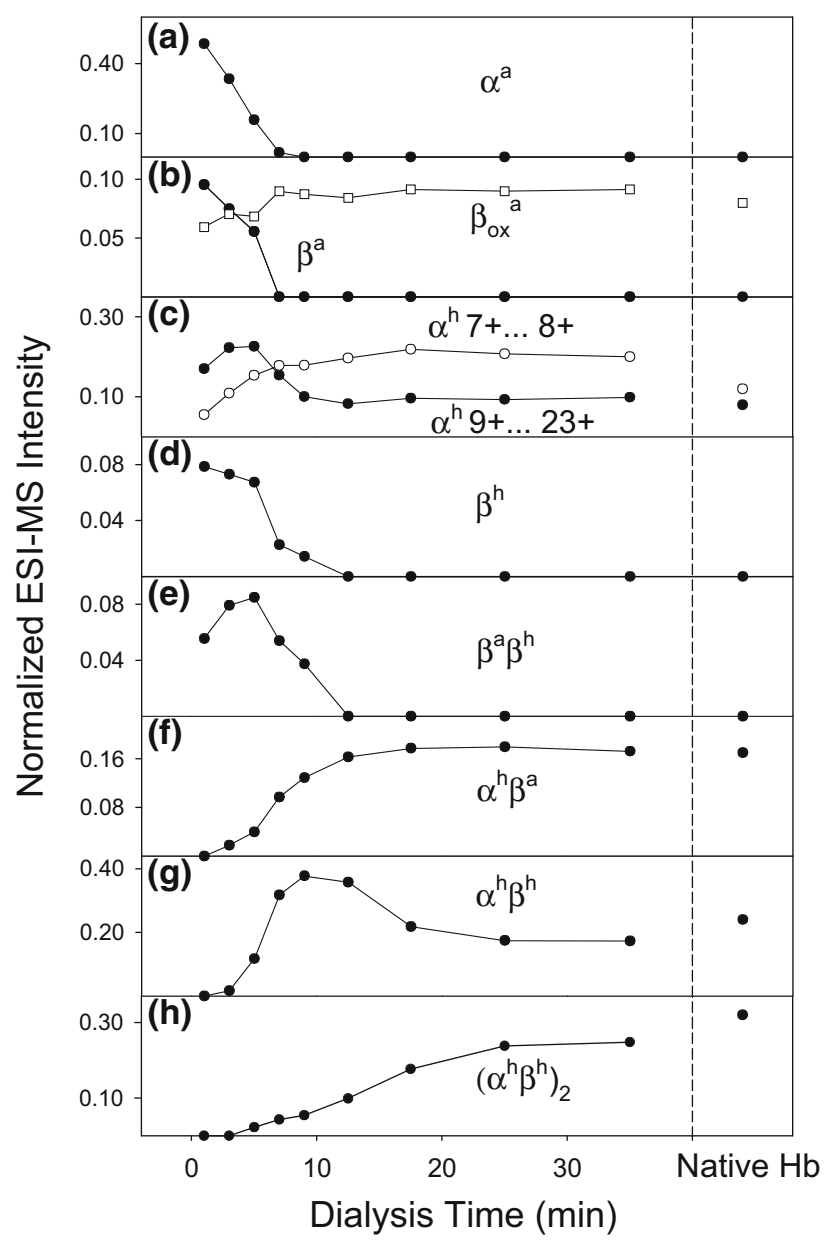

Figure 6. Normalized intensity-time profiles extracted from ESI mass spectra recorded during hemoglobin folding and assembly; (a)-(d), monomeric species; (e)-(g), dimeric species, (h) hemoglobin tetramer. Data in panels (a) and (c)-(h) represent intensity sums for all charge states corresponding to a specific heme binding state or quaternary structure. Different time profiles for high and low charge states were only observed in the case of $\alpha^{\mathrm{h}}$; those data are displayed separately (c). Data for native hemoglobin (based on the spectrum in Figure 3a) are included for comparison in each panel.

before dropping to a level close to 0.2 (Figure $6 \mathrm{~g}$ ). Following an initial lag phase, tetrameric $\mathrm{Hb}$ exhibits a slow and steady increase up to a maximum of 0.25 towards the end of the experimental time window (Figure 6h).

As noted in previous studies [61, 64], a certain fraction of $\beta$-globin carries a +32 Da modification (signals labeled $\beta_{\mathrm{ox}}$ in Figure $3 \mathrm{c}$ inset, Figure $6 \mathrm{~b}$ ). This effect is attributed to partial methionine oxidation, a notion that is consistent with the known chemical behavior of Met residues [74] and with peptide mapping studies on $\beta$-globin [75]. Interestingly, this modification does not preclude $\beta$-globin from participating in $\mathrm{Hb}$ assembly; MS/MS experiments reveal the presence of modified $\beta$-globin in $\alpha^{\mathrm{h}} \beta^{\mathrm{a}}, \alpha^{\mathrm{h}} \beta^{\mathrm{h}}$, and $\left(\alpha^{\mathrm{h}} \beta^{\mathrm{h}}\right)_{2}$ (data not shown). This observation is consistent with previous biochemical data [75], and with the fact that none of the three $\beta$ Met residues is directly involved in heme binding or protein-protein interactions [21].

The time profiles in Figure 6 allow an overall mechanism for the refolding and assembly of $\mathrm{Hb}$ to be proposed (Figure 7). The data in Figure 6a and c suggest that folded holo- $\alpha$-globin is formed in a stepwisesequential manner from largely unfolded apo-protein, via unfolded holo- $\alpha$-globin as reaction intermediate. The situation is less clear for monomeric $\beta$-globin, as both its apo and holo forms disappear from the spectrum in parallel (Figure $6 \mathrm{~b}$ and d). Possibly $\alpha^{\mathrm{h}} \beta^{\mathrm{h}}$ is formed by binding of $\alpha^{\mathrm{h}}$ to $\beta^{\mathrm{h}}$, and $\alpha^{\mathrm{h}} \beta^{\mathrm{a}}$ by binding of $\alpha^{\mathrm{h}}$ to $\beta^{\mathrm{a}}$. Based on the characteristic rise and drop of the profile in Figure $6 \mathrm{~g}, \alpha^{\mathrm{h}} \beta^{\mathrm{h}}$ appears to be a direct precursor of the $\left(\alpha^{\mathrm{h}} \beta^{\mathrm{h}}\right)_{2}$ heterotetramer. The subunit constituents of the heterodimer likely interact through their $\alpha 1 \beta 1$ interface $[18,19]$. The question whether $\alpha^{\mathrm{h}} \beta^{\mathrm{a}}$ is another direct precursor of tetrameric hemoglobin or an off-pathway complex cannot be decided with certainty from the data presented here. Certainly, $\beta^{\mathrm{a}} \beta^{\mathrm{h}}$ is an off-pathway species, as all of the contacts between the two subunits are non-native and have to be disrupted in order for $\alpha^{\mathrm{h}} \beta^{\mathrm{h}}$ or $\left(\alpha^{\mathrm{h}} \beta^{\mathrm{h}}\right)_{2}$ to form.

In general terms, the mechanism proposed in Figure 7 suggests a hierarchical sequence of events, where a certain degree of folding at the monomer level precedes the assembly of heterodimers, ultimately resulting in the formation of heterotetramers. Hierarchical folding schemes of this type have previously been deduced for other multi-protein complexes using a variety of different experimental approaches [76]. For the conditions used in this study, both $\alpha$ - and $\beta$-globin are capable of binding heme in their monomeric forms. This behavior is different from the mechanism inferred from acidinduced unfolding experiments, which suggested that heme binding to $\beta$-globin can take place only after the formation of a $\alpha^{\mathrm{h}} \beta^{\mathrm{a}}$ heterodimer [60]. Thus, the data presented here do not provide support for the idea that $\alpha^{\mathrm{h}} \beta^{\mathrm{a}}$ is an obligatory intermediate en route towards $\left(\alpha^{\mathrm{h}} \beta^{\mathrm{h}}\right)_{2}$ [43]. As noted above, however, likely the exact sequence of events during $\mathrm{Hb}$ folding and assembly in vitro can be modulated by external conditions such as solvent, $\mathrm{pH}$, presence of chaperones, etc. [45].

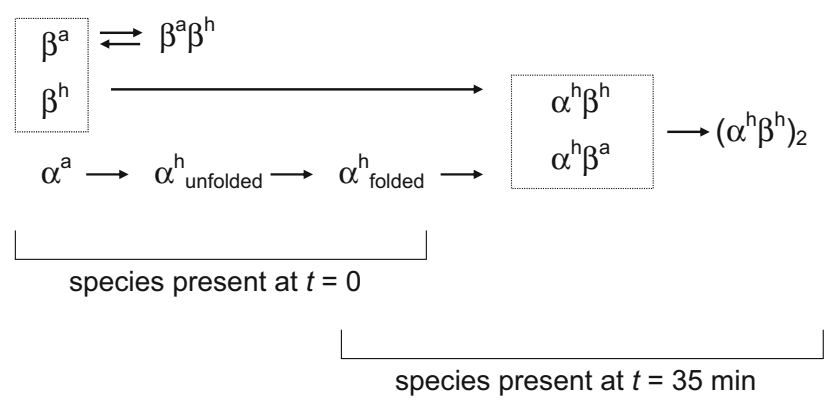

Figure 7. Proposed mechanism of hemoglobin assembly for the conditions used in this study. Further information is given in the text. 


\section{Conclusions}

Exposure of $\mathrm{Hb}$ to $\mathrm{pH} 10.0 / 40 \% \mathrm{ACN}$ induces the breakdown of the protein's quaternary structure and significant unfolding. The native heme-protein interactions become largely disrupted. In contrast to the more commonly employed acidic unfolding conditions, denaturation of $\mathrm{Hb}$ in $\mathrm{pH} 10.0 / 40 \%$ ACN is highly reversible. Optical spectroscopy as well as ESI-MS show that the properties of refolded hemoglobin are very similar to those of the protein before unfolding. This demonstrates that the spontaneous self-assembly of $\mathrm{Hb}$ from highly unfolded subunits can take place in the absence of cellular chaperones. Experiments employing an online dialysis cell allow $\mathrm{Hb}$ refolding to be monitored by ESI-MS in a time-dependent fashion. The capability of ESI-MS to distinguish coexisting protein conformations, ligand binding states, and quaternary structures provides detailed insights into the mechanism of this coupled folding/binding process. The on-line dialysis approach developed for this work could also be useful for monitoring the assembly of other protein complexes. The experiments described here were carried out on ferri-hemoglobin. In future work, we will attempt to reconstitute the protein in its physiologically active ferro $\left(\mathrm{Fe}^{2+}\right)$ form. Those studies will require a careful control of the redox conditions. Subsequent $\mathrm{O}_{2}$-binding tests will provide a stringent test for the nativeness of the refolded ferro- $\mathrm{Hb}$.

\section{Acknowledgments}

This work was supported by the Natural Sciences and Engineering Research Council of Canada (NSERC), the Canada Foundation for Innovation (CFI), and the Canada Research Chairs Program. The authors thank Dr. M. J. Stillman and Dr. R. E. H. Hudson for access to their optical spectrometers, and Dr. P. L. Ferguson for critical reading of the manuscript.

\section{References}

1. Dobson, C. M. Experimental Investigation of Protein Folding and Misfolding. Methods 2004, 34, 4-14.

2. Daggett, V.; Fersht, A. The Present View of the Mechanism of Protein Folding. Nat. Rev. Mol. Cell Biol. 2003, 4, 497-502.

3. Onuchic, J. N.; Wolynes, P. G. Theory of Protein Folding. Curr. Opin. Struct. Biol. 2004, 14, 70-75.

4. Seckler, R. Assembly of Multi-Subunit Sstructures. In Mechanisms of Protein Folding; Pain, R. H., Ed.; Oxford University Press: Oxford, 2000.

5. Baker, D.; Eaton, W. A. Folding and Binding. Curr. Opin. Struct. Biol. 2004, 14, 67-69.

6. Dyson, H. J.; Wright, P. E. Coupling of Folding and Binding for Unstructured Proteins. Curr. Opin. Struct. Biol. 2002, 12, 54-60.

7. Ma, B.; Shatsky, M.; Wolfson, H. J.; Nussinov, R. Multiple Diverse Ligands Binding at a Single Protein Site: A Matter of Preexisting Populations. Protein Sci. 2002, 11, 184-197.

8. Verkhivker, G. M.; Bouzida, D.; Gehlhaar, D. K.; Rejto, P. A.; Freer, S. T.; Rose, P. W. Simulating Disorder-Order Transition in Molecular Recognition of Unstructured Proteins: Where Folding Meets Binding. Proc. Natl. Acad. Sci. U.S.A. 2003, 100, 5148-5153.

9. Wittung-Stafshede, P. Role of Cofactors in Protein Folding. Acc. Chem. Res. 2002, 35, 201-208.

10. Loo, J. A. Noncovalent Protein-Ligand Complexes. In The Encyclopedia of Mass Spectrometry; Gross, M. L.; Caprioli, R. M. Eds.; Elsevier: Amsterdam, 2005; Vol. II; pp 289-299.

11. Donald, L. J.; Stokell, D. J.; Holliday, N. J.; Ens, W.; Standing, K. G.; Duckworth, H. W. Multiple Equilibria of the Escherichia coli Chaperonin GroES Revealed by Mass Spectrometry. Protein Sci. 2005, 14, 1375-1379.

12. Fändrich, M.; Tito, M. A.; Leroux, M. R.; Rostom, A. A.; Hartl, F. U.; Dobson, C. M.; Robinson, C. V. Observation of the Noncovalent
Assembly and Disassembly Pathways of the Chaperone Complex MtGimC by Mass Spectrometry. Proc. Natl. Acad. Sci. U.S.A. 2000, 97 , 14151-14155.

13. Heck, A. J. R.; Van den Heuvel, R. H. H. Investigation of Intact Protein Complexes by Mass Spectrometry. Mass Spectrom. Rev. 2004, 23, $368-$ 389.

14. Chowdhury, S. K.; Katta, V.; Chait, B. T. Probing Conformational Changes in Proteins by Mass Spectrometry. J. Am. Chem. Soc. 1990, 112, 9012-9013.

15. Pan, J. X.; Rintala-Dempsey, A.; Li, Y.; Shaw, G. S.; Konermann, L. Folding Kinetics of the S100A11 Protein Dimer Studied by TimeResolved Electrospray Mass Spectrometry and Pulsed Hydrogen-Deuterium Exchange. Biochemistry 2006, 45, 3005-3013.

16. Kaltashov, I. A.; Eyles, S. J. Studies of Biomolecular Conformations and Conformational Dynamics by Mass Spectrometry. Mass Spectrom. Rev. 2002, 21, 37-71.

17. Kaltashov, I. A.; Eyles, S. J. Mass Spectrometry in Biophysics; John Wiley and Sons, Inc.: Hoboken, NJ, 2005.

18. Perutz, M. F.; Muirhead, H.; Cox, J. M.; Goaman, L. C. G. Threedimensional Fourier Synthesis of Horse Oxyhemoglobin at 2.8 Angstrom: The Atomic Model. Nature 1968, 219, 131-139.

19. Bunn, H. F.; Forget, B. G. Hemoglobin: Molecular, Genetic, and Clinical Aspects; W. B. Saunders Company: Philadelphia, 1986.

20. Perutz, M. F. Stereochemistry of Cooperative Effects in Hemoglobin. Nature 1970, 228, 726-739.

21. Mueser, T. C.; Rogers, P. H.; Arnone, A. Interface Sliding as Illustrated by the Multiple Quaternary Structures of Liganded Hemoglobin. Biochemistry 2000, 39, 15353-15364.

22. Samuni, U.; Roche, C. J.; Dantskar, D.; Juszczak, L. J.; Friedman, J. M. Modulation of Reactivity and Conformation within the T-Quaternary State of Human Hemoglobin: The Combined Use if Mutagenesis and Sol-Gel Encapsulation. Biochemistry 2006, 45, 2820-2835.

23. Englander, J. J.; Del Mar, C.; Li, W.; Englander, S. W.; Kim, J. S.; Stranz, D. D.; Hamuro, Y.; Woods, V. L., Jr. Protein Structure Change Studied by Hydrogen-Deuterium Exchange, Functional Labeling, and Mass Spectrometry. Proc. Natl. Acad. Sci. U.S.A. 2003, 100, 7057-7062.

24. Eaton, W. A.; Henry, E. R.; Hofrichter, J.; Mozzarelli, A. Is Cooperative Oxygen Binding by Hemoglobin Really Understood. Nat. Struct. Biol. $1999,6,351-358$.

25. Kellett, G. L.; Gutfreund, H. Reaction of Hemoglobin Dimers after Ligand Dissociation. Nature 1970, 227, 921-926.

26. Hargrove, M. S.; Whitaker, T.; Olson, J. S.; Vali, R. J.; Mathews, A. J. Quaternary Structure Regulates Hemin Dissociation from Human Hemoglobin. J. Biol. Chem. 1997, 272, 17385-17389.

27. Leutzinger, Y.; Beychok, S. Kinetics and Mechanism of Heme-Induced Refolding of Human $\alpha$-globin. Proc. Natl. Acad. Sci. U.S.A. 1981, 78, $780-784$.

28. Kawamura-Konishi, Y.; Chiba, K.; Kihara, H.; Suzuki, H. Kinetics of the Reconstitution of Hemoglobin from Semihemoglobins $\alpha$ and $\beta$ with Heme. Eur. Biophys. J. 1992, 21, 85-92.

29. Ip, S. H. C.; Johnson, M. L.; Ackers, G. K. Kinetics of Deoxyhemoglobin Subunit Dissociation Determined by Haptoglobin Binding: Estimation of the Equilibrium Constant from Forward and Reverse Rates. Biochemistry 1976, 15, 654-660.

30. Griffon, N.; Baudin, V.; Dieryck, W.; Dumoulin, A.; Pagnier, J.; Poyart, C.; Marden, M. C. Tetramer-Dimer Equilibrium of Oxyhemoglobin Mutants Determined from Auto-Oxidation Rates. Protein Sci. 1998, 7, 673-680.

31. Schaeffer, J. R.; McDonald, M. J.; Turci, S. M.; Dinda, D. M.; Bunn, H. F. Dimer-Monomer Dissociation of Human Hemoglobin A. J. Biol. Chem. 1984, 259, 14544-14547.

32. Rollema, H. S.; Gros, G.; Bauer, C. pH Changes Accompanying the Association of Isolated $\alpha$ and $\beta$ Chains of Human Hemoglobin. J. Biol. Chem. 1980, 255, 2756-2760.

33. Joshi, A. A.; McDonald, M. J. Role of $\alpha$ and $\beta$ Carboxyl-Terminal Residues in the Kinetics of Human Oxyhemoglobin Dimer Assembly. J. Biol. Chem. 1994, 269, 8549-8553.

34. McGovern, P.; Reisberg, P.; Olson, J. S. Aggregation of Deoxyhemoglobin Subunits. J. Biol. Chem. 1976, 251, 7871-7879.

35. McDonald, M. J.; Turci, S. M.; Mrabet, N. T.; Himmelstein, B. P.; Bunn, H. F. The Kinetics of Assembly of Normal and Variant Human Oxyhemoglobins. J. Biol. Chem. 1987, 262, 5951-5956.

36. Kawamura, Y.; Hasumi, H.; Nakamura, S. Kinetic Studies on the Reconstitution of Deoxyhemoglobin from Isolated $\alpha$ and $\beta$ Chains. J. Biochem. 1982, 92, 1227-1233.

37. Adachi, K.; Yang, Y.; Joshi, A. A.; Vasudevan, G.; Morris, A.; McDonald, M. J. Consequences of $\beta 16$ and $\beta 112$ Replacements on the Kinetics of Hemoglobin Assembly. Biochem. Biophys. Res. Commun. 2001, 289, 75-79.

38. Shaeffer, J. R.; McDonald, M. J.; Bunn, H. F. Assembly of Normal and Abnormal Human Hemoglobins. Trends Biochem. Sci. 1981, 6, 158-161.

39. Bunn, H. F.; McDonald, M. J. Electrostatic Interactions in the Assembly of Hemoglobin. Nature 1983, 306, 498-500.

40. Mrabet, N. T.; McDonald, M. J.; Turci, S.; Sarkar, R.; Szabo, A.; Bunn H. F. Electrostatic Attraction Governs the Dimer Assembly of Human Hemoglobin. J. Biol. Chem. 1986, 261, 5222-5228.

41. Yamaguchi, T.; Yang, Y.; McDonald, M. J.; Adachi, K. Surface and Interface $\beta$-Chain Residues Synergistically Affect Hemoglobin Assembly. Biochem. Biophys. Res. Commun. 2000, 270, 683-687. 
42. Adachi, K.; Zhao, Y.; Surrey, S. Effects of Heme Addition on Formation of Stable Human Globin Chains and Hemoglobin Subunit Assembly in a Cell-Free System. Arch. Biochem. Biophys. 2003, 413, 99-106.

43. Vasudevan, G.; McDonald, M. J. Ordered Heme Binding Ensures the Assembly of Fully Functional Hemoglobin: A Hypothesis. Curr. Prot. Pept. Sci. 2002, 3, 461-466.

44. Vasudevan, G.; McDonald, M. J. Spectral Demonstration of Semihemoglobin Formation During CN-Hemin Incorporation into Human Apohemoglobin. J. Biol. Chem. 1997, 272, 517-524.

45. Yip, Y. K.; Waks, M.; Beychok, S. Reconstitution of Native Human Hemoglobin from Separated Globin Chains and Alloplex Intermediates. Proc. Natl. Acad. Sci. U.S.A. 1977, 74, 64-68.

46. Luzzatto, L.; Notaro, R. Haemoglobin's Chaperone. Nature 2002, 417, 703-704.

47. Komar, A. A.; Kommer, A.; Krasheninnikov, I. A.; Spirin, A. S. Cotranslational Folding of Globin. J. Biol. Chem. 1997, 272, 10646-10651.

48. Komar, A. A.; Kommer, A.; Krasheninnikov, I. A.; Spirin, A. S. Cotranslational Heme Binding to Nascent Globin Chains. FEBS Lett. 1993, 326, 261-263.

49. Kihm, A. J.; Kong, Y.; Hong, W.; Russel, J. E.; Rouda, S.; Adachi, K.; Simon, M. C.; Blobel, G. A.; Weiss, M. J. An Abundant Erythroid Protein that Stabilizes Free $\alpha$-Hemoglobin. Nature 2002, 417, 758-763.

50. Baudin-Creuza, V.; Vasseur-Godbillon, C.; Pato, C.; Prehu, C.; Wajcman, H.; Marden, M. C. Transfer of Human $\alpha$ - to $\beta$-Hemoglobin via its Chaperone Protein. J. Biol. Chem. 2004, 279, 36530-36533.

51. Santiveri, C. M.; Perez-Canadillas, J. M.; Viadivelu, M. K.; Allen, M. D.; Rutherford, T. J.; Watkins, N. A.; Bycroft, M. NMR Structure of the $\alpha$-Hemoglobin Stabilizing Protein. J. Biol. Chem. 2004, 279, 34963-34970.

52. Hodge, D.; Coghill, E.; Keys, J.; Maguire, T.; Hartman, B.; McDowall, A.; Weiss, M.; Grimmond, S.; Perkins, A. A global role for EKLF in Definitive and Primitive Erythropoiesis. Blood 2006, 15, 3359-3370.

53. Feng, L.; A., G. D.; Zhou, S.; Gu, L.; Kong, Y.; Li, J.; Hu, M.; Yan, N.; Lee, C.; Rich, A. M.; Armstrong, R. S.; Lay, P. A.; Gow, A. J.; Weiss, M. J.; Mackay, J. P.; Shi, Y. Molecular Mechanism of AHSP-Mediated Stabilization of $\alpha$-Hemoglobin. Cell 2004, 119, 629-640.

54. Feng, L.; Zhou, S.; Gu, L.; Gell, D. A.; Mackay, J. P.; Weiss, M. J.; Gow, A. J.; Shi, Y. Structure of Oxidized $\alpha$-Hemoglobin Bound to AHSP Reveals a Protective Mechanism for Haem. Nature 2005, 435, 697-701.

55. Yamaguchi, T.; Pang, J.; Reddy, K. S.; Witkowska, H. E.; Surrey, S.; Adachi, K. Expression of Soluble Human $\beta$-Globin Chains in Bacteria and Assembly In Vitro with $\alpha$-Globin Chains. J. Biol. Chem. 1996, 271, 26677-26683.

56. Versluis, C.; Heck, A. J. R. Gas-Phase Dissociation of Hemoglobin. Int. J. Mass Spectrom. 2001, 210/211, 637-649.

57. Schmidt, A.; Bahr, U.; M., K. Influence of Pressure in the First Pumping Stage on Analyte Desolvation and Fragmentation in Nano-ESI MS. Anal. Chem. 2001, 73, 6040-6046.

58. Tahallah, N.; Pinkse, M.; Maier, C. S.; Heck, A. J. R. The Effect of the Source Pressure on the Abundance of Ions of Noncovalent Protein Assemblies in an Electrospray Ionization Orthogonal Time-of-Flight Instrument. Rapid Commun. Mass Spectrom. 2001, 15, 596-601.
59. Chernushevich, I. V.; Thomson, B. A. Collisional Cooling of Large Ions in Electrospray Mass Spectrometry. Anal. Chem. 2004, 76, 1754-1760.

60. Griffith, W. P.; Kaltashov, I. A. Highly Asymmetric Interactions Between Globin Chains During Hemoglobin Assembly Revealed by Electrospray Ionization Mass Spectrometry. Biochemistry 2003, 42, 10024-10033.

61. Simmons, D. A. Wilson, D. J.: Lajoie, G. A.; Doherty-Kirby, A. Konermann, L. Subunit Disassembly and Unfolding Kinetics of Hemoglobin Studied by Time-Resolved Electrospray Mass Spectrometry. Biochemistry 2004, 43, 14792-14801.

62. Adams, P. A. The Kinetics and Mechanism of the Recombination Reaction between Apomyoglobin and Haemin. Biochem. J. 1976, 159, 371-376.

63. Adams, P. A. The Kinetics of the Recombination Reaction between Apomyoglobin and Alkaline Hematin. Biochem. J. 1977, 163, 153-158.

64. Hossain, B. M.; Konermann, L. Pulsed Hydrogen/Deuterium Exchange MS/MS for Studying the Relationship Between Noncovalent Protein Complexes in Solution and in the Gas Phase after Electrospray Ionization. Anal. Chem. 2006, 78, 1613-1619.

65. Grandori, R. Origin of the Conformation Dependence of Protein Charge-State Distributions in Electrospray Ionization Mass Spectrometry. J. Mass Spectrom. 2003, 38, 11-15.

66. Simmons, D. A.; Dunn, S. D.; Konermann, L. Conformational Dynamics of Partially Denatured Myoglobin Studied by Time-Resolved Electrospray Mass Spectrometry with Online Hydrogen-Deuterium Exchange. Biochemistry 2003, 42, 5896-5905.

67. Konermann, L.; Douglas, D. J. Unfolding of Proteins Monitored by Electrospray Ionization Mass Spectrometry: A Comparison of Positive and Negative Ion Modes. J. Am. Soc. Mass Spectrom. 1998, 9, 1248-1254.

68. Grycynski, Z.; Lubkowski, J.; Bucci, E. Intrinsic Fluorescence of Hemoglobins and Myoglobins. Methods Enzymol. 1997, 278, 538-569.

69. Hirsch, R. E. Front-Face Fluorescence Spectroscopy of Hemoglobins. Methods Enzymol. 1994, 232, 231-246.

70. Chiu, F.; Vasudevan, G.; Morris, A.; McDonald. Fluorescence Studies of Human Semi- $\beta$-Hemoglobin Assembly. Biochem. Biophys. Res. Commun. $1998,242,365-368$

71. Crespin, M. O.; Boys, B. L.; Konermann, L. The Reconstitution of Unfolded Myoglobin with Hemin Dicyanide is Not Accelerated by Fly Casting. FEBS Lett. 2005, 579, 271-274.

72. Johnson, W. C. Secondary Structure of Proteins Through Circular Dichroism Spectroscopy. Annu. Rev. Biophys. Biophys. Chem. 1988, 17, 145-166.

73. Sage, J. T.; Morikis, D.; Champion, P. M. Spectroscopic Studies of Myoglobin at Low pH: Heme Structure and Ligation. Biochemistry 1991, 30, 1227-1237.

74. Creighton, T. E. Proteins; W. H. Freeman and Co: New York, 1993.

75. Amiconi, G.; Ascoli, F.; Barra, D.; Bertollini, A.; Matarese, R. M.; Verzili, D.; Brunori, M. Selective Oxidation of Methionine $\beta(55)$ D6 at the $\alpha 1 \beta 1$ Interface in Hemoglobin Completely Destabilizes the T-state. J. Biol. Chem. 1989, 264, 17745-17749.

76. Pain, R. H. Mechanisms of Protein Folding, 2nd ed.; Oxford University Press: New York, 2000. 